\title{
MULTICULTURALISMO Y DERECHOS HUMANOS
}

\author{
MULTICULTURALISM AND HUMAN RIGHTS
}

\author{
MIGUEL CARBONELL ${ }^{1}$
}

\begin{abstract}
RESUMO: O artigo apresenta o panorama do debate sobre os direitos humanos no contexto do multiculturalismo. São abordadas as questões dos direitos coletivos e da proteção de direitos humanos em sociedades internamente multiculturais. A conclusão aponta dilemas dos direitos de grupos.

PALAVRAS-CHAVE: Multiculturalismo; Direitos Humanos; Direitos Coletivos.
\end{abstract}

ABSTRACT: The article outlines the debate on human rights in the context of multiculturalism. It approaches issues such as collective rights and the protection of human rights in internally multicultural societies. The conclusion discusses dilemmas of group rights.

KEYWORDS: Multiculturalism; Human Rights; Collective Rights.

SUMÁRIO: 1. Multiculturalismo e Direitos: um debate aberto e complexo; 2. As Etapas do Debate; 3. Diferenças e Desigualdades; 4. Os Argumentos sobre os Direitos Culturalmente Diferenciados; 5 . Que Direitos para as Sociedades Multiculturais? 6. A Guisa de Conclusão: os dilemas dos direitos de grupos; Referências.

SUMMARY: 1. Multiculturalism and Rights: an open and complex debate; 2 . The Steps in the Debate; 3. Differences and Inequalities; 4. The Arguments on Culturally Differentiated Rights; 5. What Rights for Multicultural Societies?; Concluding Remarks: the dilemmas of group rights; References.

\section{MULTICULTURALISMO Y DERECHOS: UN DEBATE ABIERTO $Y$ COMPLEJO}

En los últimos años hemos asistido a la inserción, dentro de los debates sobre el contenido y papel de las Constituciones, del tema del multiculturalismo y de los derechos de las minorías. Desde luego que la protección de las minorías ha sido un asunto central del constitucionalismo desde sus orígenes. La función de los derechos fundamentales y de los jueces constitucionales, que son dos instituciones básicas (esenciales, mejor dicho) del paradigma del

\footnotetext{
Artigo recebido em 24.09.2013. Artigo aceito para publicação em 30.09.2013 mediante convite. ${ }^{1}$ Professor do Instituto de Investigaciones Jurídicas da Universidad Nacional Autónoma de México. carbonel@servidor.unam.mx
} 
Estado constitucional son típicamente contramayoritarias y tienen como uno de sus objetivos centrales la protección de las minorías ${ }^{2}$.

Pero el debate actual no trata sobre el clásico enfoque relativo a la protección constitucional que debía darse a las minorías, sino que ha avanzado por su propia línea discursiva, diseñando una ruta que ha venido a poner en crisis varios de los conceptos fundamentales con los que la teoría constitucional había trabajado desde su nacimiento y, en particular, de algunos que se habían desarrollado a partir de la Segunda Guerra Mundial que es cuando se consolida el modelo de Constitución que rige en la actualidad ${ }^{3}$.

La discusión sobre el multiculturalismo se ha extendido hacia muchas áreas del conocimiento social, abarcando temas referidos a la protección jurídica de las diferentes culturas que conviven al interior de un Estado, pero replanteando también cuestiones que tienen que ver con los derechos fundamentales, como pueden ser las concepciones de la autonomía moral de los individuos o los límites de la tolerancia hacia prácticas no liberales de organización societaria, para llegar incluso al propio concepto de cultura en tanto que objeto a proteger por el sistema constitucional de derechos fundamentales.

En cualquier caso, la reflexión teórica ha surgido como producto de necesidades absolutamente prácticas. En los últimos años se han exacerbado como nunca las pasiones nacionalistas y culturalistas, lo cual ha generado conflictos de gran magnitud derivados en parte de los retos que para la convivencia y organización estatal representa el multiculturalismo ${ }^{4}$.

Tal parece que el fenómeno de la globalización, el crecimiento expansivo de los alcances de los mercados y la imposición planetaria de una serie de pautas culturales y de valores sociales, se ha correspondido en el ámbito de los Estados-nación con un "retorno a la comunidad", con un redescubrimiento del valor de lo propio, de lo distinto o de lo antiguo ${ }^{5}$. En este sentido, la globalización, aunque muchas veces deliberadamente se ignore por algunos de sus teorizadores, ha supuesto un movimiento doble: de una parte, hacia la internacionalización y la reducción del tiempo y el espacio -ilustrada por ejemplo en la velocidad de los mercados financieros para movilizar planetariamente y en tiempo real divisas y capitales-; por otra, en un resurgimiento de los

\footnotetext{
${ }^{2}$ Este tema ha sido abordado por varios de los trabajos que figuran en la obra colectiva El Canon Neoconstitucional, Madrid: Trotta, 2010 (sobre todo en los ensayos de Ronald Dworkin y de Juan carlos Bayón).

${ }^{3}$ Ver Aragón, Manuel, "La Constitución como Paradigma" en la obra colectiva Teoría de la Constitución. Ensayos Escogidos, México, IIJ-UNAM, Porrúa, 2000, p. 109 y ss.

${ }^{4}$ Se ha estimado que entre 1945 y 1975 ha habido diez millones de muertes relacionadas con la violencia étnica; de entonces a esta fecha la cifra sigue incrementándose por los hechos de Ruanda y Zaire a mediados de los 90, los de Bosnia y Croacia también en esa década y los de Punjab y Sri Lanka un poco antes. Sobre este punto, Kellas, James, The Politics of Nationalism and Ethnicity, $2^{\mathrm{a}}$. edic., Nueva York, St. Martin's Press, 1998.

${ }^{5}$ Ianni, Octavio, La Era de la Globalización, México, Siglo XXI editores, 1999, p. 127 y ss.
} 
localismos y una revitalización de los "discursos identitarios", ya sea de raíz religiosa, cultural, étnica o nacional ${ }^{6}$. Es en este último punto donde se instala en definitiva la problemática multiculturalista.

Will Kymlicka identifica cuatro factores que han incidido en la explosión del interés en torno a la protección y acomodo de las minorías dentro de los Estados democráticos contemporáneos ${ }^{7}$ : a) en primer lugar, la caída de los regímenes comunistas de Europa del Este, que desató una oleada de nacionalismos étnicos esa parte del mundo; b) en segundo término, el reto del acomodo para los inmigrantes, cuestión que es particularmente intensa dentro de las democracias ricas de Europa y en Estados Unidos; c) en tercer lugar, el resurgimiento de los movimientos indígenas y su movilización política, que ha generado un efecto importante sobre varios de los textos constitucionales de América Latina; y d) la creciente y constante amenaza de secesión que se está generando en varios países, como por ejemplo en Canadá, Gran Bretaña, Bélgica y España.

Sea como sea, el tema del multiculturalismo no es de carácter exclusivamente teórico en la medida en que involucra cuestiones prácticas que tienen que resolver muchas de las democracias contemporáneas, incluyendo por supuesto la incipiente democracia mexicana ${ }^{8}$. Como apunta Neus Torbisco, "las democracias con demócratas, todavía no han superado ni mucho menos resuelto los problemas derivados de la diversidad cultural".

Las dificultades mayores del debate multiculturalista se encuentran al momento de traducir normativamente las opciones tomadas con base en posturas propias de la filosofía moral o política o incluso de la antropología. El discurso multiculturalista es de aquellos que se mueve bien "en las alturas", pero que presenta graves problemas cuando se quiere aplicar a realidades que suelen ser muy complejas, como lo demuestra entre otros el caso del Estado mexicano.

\footnotetext{
${ }^{6}$ Vallespín, Fernando, El Futuro de la Política, Madrid, Taurus, 2000, p. 29-30. En el mismo sentido, Isidoro Moreno destaca que la mundialización ha generado dos dinámicas complementarias y opuestas: "la dinámica de la globalización y la dinámica de la reafirmación identitaria, la que comienza a denominarse como dinámica de la localización", "Mundialización, globalización y nacionalismos: la quiebra del modelo de Estado-nación" en Carbonell, Miguel y Vázquez, Rodolfo (compiladores), Estado Constitucional y Globalización, México, IIJ-UNAM, Porrúa, 2001.

7 La Política Vernácula. Nacionalismo, Multiculturalismo y Ciudadanía, Barcelona, Paidós, 2003, p. 30.

${ }^{8}$ Como señala Will Kymlicka, “...minorías y mayorías se enfrentan cada vez más respecto de temas como los derechos lingüisticos, la autonomía regional, la representación política, el currículum educativo, las reivindicaciones territoriales, la política de inmigración y naturalización, e incluso acerca de símbolos nacionales, como la elección del himno nacional y las festividades oficiales. Encontrar respuestas moralmente defendibles y políticamente viables a dichas cuestiones constituye el principal desafío al que se enfrentan las democracias en la actualidad", Ciudadanía Multicultural. Una Teoría Liberal de los Derechos de las Minorías, Barcelona, Paidós, 1996, p. 13; del mismo autor, "Derechos Individuales y Derechos de grupo en la Democracia Liberal" en Del Aguila, Rafael, Vallespín, Fernando y otros, La Democracia en sus Textos, Madrid, Alianza Editorial, 1998, p. 413 y ss.
} 
En este contexto, una teoría comprensiva de los derechos fundamentales no puede dejar de plantearse los retos que el panorama multicultural está poniendo en la mesa de discusión de muchos países; las soluciones, como se intentará poner de manifiesto en las páginas siguientes, no son fáciles y las exigencias de replanteamiento de categorías clásicas dentro del derecho constitucional están a la orden del día.

Ante este panorama, las modernas democracias no pueden seguir tratando a las minorías como si no existieran o, peor aún, con la única arma de la represión a los que son diferentes por causa de su religión, de su origen étnico o de su pertenencia cultural. Hoy en día el reto puede sintetizarse en una frase que ha sido muy utilizada, pero quizá no tan comprendida como sería necesario: hacer posible la convivencia intercultural con el respeto a la diversidad. Ese es el signo que marcará, durante las décadas que siguen, la historia de muchos países, entre los que desde luego se encuentran varios de América Latina.

¿Tiene algo que aportar la teoría del derecho constitucional y de los derechos fundamentales al debate multiculturalista? La respuesta, al tenor de la exposición que se realiza en los siguientes apartados, debe ser necesariamente positiva, puesto que en último término se trata de resolver el clásico problema de las relaciones entre la mayoría y las minorías, aunque en esta ocasión no estén determinadas según los parámetros clásicos con los que ha operado típicamente el constitucionalismo.

Por un lado, la intervención del derecho constitucional, como ya se apuntaba, debe darse por necesidades muy prácticas, que en parte se han ido resolviendo en muchos países. Al reconocer los derechos de las minorías -otorgándoles incluso rango constitucional- se han evitado escenarios de guerras, terrorismo y violencia intercultural en varios países democráticos ${ }^{9}$; en otros casos, cuando las minorías han sido sojuzgadas o incluso reprimidas no se ha podido lograr un ambiente que permita la convivencia pacífica entre los grupos étnico-culturales.

Desde otro punto de vista, al poner el debate sobre los derechos de las minorías en el nivel de los derechos fundamentales, se evita dejar el tema dentro de la órbita de las políticas públicas, que según algunos autores pueden ser discrecionales, experimentales y transitorias. Al considerar a las reivindicaciones de las minorías como derechos fundamentales se les enfoca desde la óptica de la dignidad y el respeto básicos que deben darse en toda sociedad democrática ${ }^{10}$.

\footnotetext{
${ }^{9}$ Como escribe Will Kymlicka, "En parte como resultado de haber adoptado estos derechos de las minorías, las democracias occidentales han aprendido a tratar la diversidad étnica de forma pacífica y democrática, con una ausencia casi completa de belicosidad, terrorismo, violencia o represión estatal", La Política Vernácula, cit., p. 12.

${ }^{10}$ Kymlicka, La Política Vernácula, cit., p. 16.
} 
Desde luego, hay que reconocer que se trata de un tema en el que no pueden ofrecerse respuestas definitivas y en el que no hay teorías consolidadas. El debate ha cambiado de forma importante en los últimos años y el reconocimiento de los derechos de las minorías, aunque presente rasgos comunes en muchos países de América Latina, se ha llevado a cabo de forma diferente en cada ordenamiento constitucional. Kymlicka señala que "A pesar de la creciente envergadura de la bibliografía sobre los derechos de las minorías aún no disponemos de una explicación sistemática sobre qué tipos de exigencias de las minorías son apropiados y en qué contextos y para qué grupos - por ejemplo, sobre cómo difieren las reclamaciones de los pueblos indígenas de las reclamaciones de otros grupos nacionales"11.

Con las salvedades de lo que más adelante se dirá, hay que afirmar también que el rubro mismo de "derechos colectivos" puede ser discutido, tal como se ha hecho en el debate multiculturalista reciente. Cuando se enfocan con algún detalle, no es difícil percibir que los derechos de las minorías generan múltiples posiciones subjetivas, algunas de las cuales tienen una expresión de carácter colectivo o grupal (por ejemplo, las vinculadas a los derechos de auto-gobierno o incluso al más amplio derecho de autodeterminación), pero otras no difieren en mucho -o en nada, mejor dicho- de los clásicos derechos de libertad o de los derechos de seguridad jurídica ${ }^{12}$.

En todo caso, conviene advertir que nos movemos sobre un terreno pantanoso y poco claro, que en muchos aspectos se encuentra apenas en construcción y sobre el que hay algunos acuerdos y muchos desacuerdos, varios de ellos muy profundos. Se trata también de una cuestión compleja en el sentido de que incorpora un abanico muy amplio de temas, que van desde la problemática que presentan los inmigrantes, hasta las reivindicaciones de los indígenas o lo que algunos textos legales, como la Constitución mexicana, considera como "comunidades equiparables".

\section{LAS ETAPAS DEL DEBATE}

Para ir comprendiendo el debate reciente sobre el multiculturalismo, quizá sea oportuno hacer un breve recorrido sobre las principales estaciones en las que ese debate se ha detenido en los años recientes. Para lograr una exposición sintética pero a la vez -espero- sustantiva, voy a seguir la síntesis elaborada por Will Kymlicka, que ha identificado tres grandes etapas en la discusión sobre el multiculturalismo y los derechos de las minorías.

A) En la primera etapa, que abarca las décadas de los años 70 y 80 , los derechos de las minorías se identifican con el comunitarismo; de hecho, el debate se parece reducir a la disputa entre comunitaristas y liberales. En este punto, la posición sobre los derechos de las minorías dependía de la propia postura sobre el comunitarismo. Quienes aceptaban la necesidad de

\footnotetext{
${ }^{11}$ Kymlicka, La Política Vernácula, cit., p. 13-14.

${ }^{12}$ Kymlicka, La Política Vernácula, cit., p. 99 y ss.
} 
que existieran derechos de las minorías sostenían que esos derechos no eran del todo compatibles con los principios del individualismo moral o de la autonomía individual que defendía el liberalismo; se decía que la personas estaban neceseriamente incrustadas en distintos roles y relaciones sociales, que determinaban su conducta y su percepción del bien, por lo que las comunidades requerían de una consideración más amplia que los individuos, a fin de asegurar la permanencia de ese contexto de elección.

En otras palabras, defender derechos de las minorías equivalía a defender posturas comunitaristas, mientras que las posiciones liberales no aceptaban tales derechos. En palabras de Kymlicka, "la defensa de los derechos de las minorías implicaba respaldar la crítica comunitarista al liberalismo y considerar que los derechos de las minorías representaban la defensa de los grupos minoritarios cohesionados y de mentalidad comunal frente a la intrusión del individualismo liberal" ${ }^{13}$.

B) En la segunda etapa el debate cambia sustancialmente ya que se reconoce que el liberalismo también pueden dar cabida a derechos de las minorías. En ese cambio concurren varias circunstancias. Una de ellas es que se comprueba que las minorías no siempre quieren ser protegidas de los avances de la modernidad, sino que, por el contrario, lo que piden es una serie de protecciones que les permitan justamente poder disfrutar de esos avances en condiciones equitativas respecto a la mayoría. Las minorías culturales dejan de ser vistas como grupos regresivos y anti-liberales porque se comprueba que su adhesión a los principios de la modernidad liberal es tan profunda e intensa como lo es en el caso de los grupos mayoritarios. Se asume que el compromiso con la autonomía individual es muy profundo y extenso en nuestras democracias contemporáneas, llegando a atravesar cualquier diferencia étnica, lingüística o religiosa.

En este punto del debate, en consecuencia, la cuestión central no responde al típico debate entre comunitaristas y liberales, sino entre diversas formas de entender el liberalismo y de llevarlo a la práctica. Algunas minorías argumentan que el reconocimiento de ciertos derechos colectivos, por ejemplo de los relacionados con su lengua, prácticas culturales e identidades, no solamente no se opone al principio de autonomía individual, sino que por el contrario es un requerimiento que viene exigido tomando a ese principio como premisa para regular la convivencia entre la mayoría y las minorías culturales dentro de un Estado.

Las preguntas clave que surgen en esta etapa del debate son al menos las siguientes: ¿si las minorías culturales son liberales ${ }^{14}$, porqué entonces

\footnotetext{
${ }^{13}$ Kymlicka, La Política Vernácula, cit., p. 32.

${ }^{14}$ No se debe pasar por alto que no todas las minorías culturales o étnicas son liberales, pero también es cierto que las minorías "típicamente anti-liberales" son, al menos en las democracias occidentales, la excepción y no la regla. Tampoco todos los derechos en favor de las minorías encajan bien en la teoría liberal, como veremos más adelante.
} 
requieren que se les reconozca un estatus jurídico particular?, ¿porqué no pueden satisfacer sus expectativas de vida con los típicos derechos fundamentales asignados a todos?, y lo más importante, ¿cómo asegurar que el reconocimiento de un estatuto jurídica particular para las minorías no representará un rompimientos de los postulados esenciales del liberalismo, es decir, hasta dónde puede llegar ese reconocimiento sin situarse fuera del ámbito liberal? Para responder a estas preguntas Kymlicka formula un par de reglas, que aunque simplifican al máximo la cuestión también sirven para aclararla: Los derechos de las minorías, nos dice este autor, son coherentes con el culturalismo liberal si a) protegen la libertad de los individuos en el seno del grupo; y b) promueven relaciones de igualdad (de no dominación) entre los grupos ${ }^{15}$.

C) La tercera etapa del debate es, según Kymlicka, en la que nos encontramos actualmente. A partir de la etapa anterior se ha empezado a generar un consenso sobre el "culturalismo liberal", que ha permitido que la discusión haya ido avanzando hacia cuestiones muy concretas que se refieren al desarrollo de políticas multiculturalistas concretas. En esta tercera etapa se abandona la idea de la neutralidad estatal y se pasa a la idea del Estado democrático protector de las naciones y nacionalidades que conviven en su interior. Se trata de discutir las formas en que se van a tutelar a las minorías nacionales, por un lado, y a los inmigrantes, por otro.

Para Kymlicka, los dos grandes avances del debate, hasta este momento, consisten en que, en primer lugar, se ha abandonado la idea de que la justicia social puede ser definida en términos de reglas que no hagan caso de las diferencias (difference-blind rules); actualmente se acepta que esas reglas pueden causar desigualdades y, por tanto, ser fuente de injusticias. El segundo avance es que hoy en día la carga de la prueba ya no corresponde a quienes defienden derechos de las minorías, sino de quienes defienden las reglas que no hacen caso de las diferencias, ya que deben probar que el status quo no crea injusticias para los grupos minoritarios.

De todo lo anterior se puede concluir que, desde hace unos años, se trata ya no de discutir si tiene preeminencia el individuo o la comunidad, si el reconocimiento de las diferencias funciona como excusa para regresar al feudalismo, o si la autonomía personal se puede desarrollar por fuera y aún en contra de todas las señas que imprime sobre cada individuo la pertenencia a un determinado grupo étnico o cultural; ahora la discusión se enfoca en la necesidad impulsar o frenar el reconocimiento de reivindicaciones normativas muy concretas y específicas. Reivindicaciones que, en una de sus variantes, asumen la forma de derechos colectivos.

Para poder comprender la regulación constitucional que en materia de multiculturalismo y derechos de las minorías existe en varios países de

\footnotetext{
${ }^{15}$ Kymlicka, La Política Vernácula, cit., p. 36.
} 
América Latina, hace falta preliminarmente repasar algunas cuestiones de orden general, como por ejemplo las posibles respuestas que el ordenamiento jurídico puede aportar en el tratamiento de las diferencias (tanto individuales como grupales). También es importante detenerse en el tema de los argumentos a favor y en contra de los derechos culturalmente diferenciados (es decir, se trata del fundamento del estatuto jurídico diferenciado que algunas minorías reclaman, ¿cómo se justifica ese trato diferente?). Por otro lado, es importante ir aterrizando el debate a fin de identificar concretamente de qué derechos hablamos cuando hacemos referencia a los derechos colectivos. Una vez que se ha ido analizando lo anterior podemos entrar al terreno de los problemas que las diferencias culturales suministran en el derecho constitucional positivo (o sea, ¿cómo hacer compatibles los derechos de las minorías con el resto de los derechos?, ¿cuáles son los sujetos a los que protegen esos derechos?, etcétera) y particularmente en el constitucionalismo de América Latina, donde el tema se ha enfocado al reconocimiento y protección de los derechos indígenas.

\section{DIFERENCIAS Y DESIGUALDADES}

Para poder entender las posibles respuestas que puede ofrecer el sistema jurídico a los planteamientos multiculturalistas habría que empezar distinguiendo entre el concepto de "diferencias" y el de "desigualdades".

Las primeras, de acuerdo con Luigi Ferrajoli, son los rasgos específicos que individualizan, haciéndolas distintas a las demás, a las personas y que, en cuanto tales, son tuteladas por los derechos fundamentales. Por su parte, las desigualdades, ya sean económicas o sociales, también según el mismo autor, son las disparidades entre sujetos producidas por la diversidad de sus derechos patrimoniales, así como de sus posiciones de poder y sujeción.

Las diferencias conforman las distintas identidades, mientras que las desigualdades configuran las diversas esferas jurídicas ${ }^{16}$. La distinción es pertinente en la medida en que suelen ir de la mano el no reconocimiento cultural con fuertes discriminaciones y situaciones sociales de infraprivilegio ${ }^{17}$, lo cual puede conducir a que se confundan unas y otras y no se aborden los problemas (y sus correspondientes soluciones) por separado.

En ambos casos el aseguramiento de los derechos que permitan las diferencias (en tanto que constituyen identidades y son por tanto la concretización de la autonomía moral de las personas) y que combatan las desigualdades (al menos aquellas que sean ilegítimas) pueden derivar en obligaciones negativas y positivas a cargo de los poderes públicos.

Para Ferrajoli hay cuatro "modelos" de relación entre el derecho y las diferencias ${ }^{18}$ :

\footnotetext{
16 "Igualdad y diferencia” en Derechos y Garantías. La Ley del más Débil, Madrid, Trotta, 1999, p. 82.

${ }^{17}$ Habermas, "La Lucha por el Reconocimiento en el Estado Democrático de Derecho" en su libro La Inclusión del Otro. Estudios de Teoría Política, Barcelona, Paidós, 1999, p. 192.

18 "Igualdad y diferencia", cit., p. 74-76.
} 
A) El primero es el modelo de la "indiferencia jurídica de las diferencias"; para este modelo las diferencias no se valorizan ni se desvalorizan, no se tutelan ni se reprimen, simplemente se las ignora. Se trata del paradigma hobbesiano del estado de naturaleza y de la libertad salvaje. En realidad ni siquiera se podría hablar, en sentido estricto, de una relación entre el derecho y las diferencias, pues en este caso las diferencias no existirían como objeto de regulación jurídica.

B) El segundo modelo es el de la "diferenciación jurídica de las diferencias", de acuerdo con el cual se valorizan algunas identidades y se desvalorizan otras; aquellas que son valorizadas (como las identidades por razón de sexo, de nacimiento, de lengua, de fe religiosa, de renta, etcétera) resultan asumidas como status privilegiados y como fuentes de derechos y poderes. Las diferencias que no son valorizadas (por ejemplo la de mujer, judío, negro, hereje, apóstata, extranjero, apátrida, etcétera) se convierten en status discriminatorios, fuentes de exclusión y de sujeción, o a veces incluso de persecución. En este caso estaríamos frente al supuesto de los ordenamientos paleoliberales del siglo pasado que, por ejemplo, reservaban el derecho al voto a los varones, blancos y terratenientes, a la vez que reconocían el derecho a la esclavitud o negaban la personalidad jurídica de las mujeres.

C) El tercer modelo es el de la "homologación jurídica de las diferencias", según el cual las diferencias son negadas e ignoradas en nombre de una abstracta afirmación de igualdad. Se trata del modelo de serialización llevado a cabo por los diversos socialismos reales y burocráticos. En este modelo se lleva a cabo una homologación, neutralización e integración de todos que elimina normativamente las diferencias y asume una identidad -en términos de sexo, clase, adhesión ideológica o religiosa- como "normal" y al mismo tiempo como "normativa".

D) El cuarto modelo es el de la "igual valoración jurídica de las diferencias"; se basa en el principio de igualdad en los derechos fundamentales y al mismo tiempo en un sistema de garantías capaces de asegurar su efectividad. De acuerdo con Ferrajoli, este modelo no ignora las diferencias sino que al asegurar la igualdad de todos en los derechos fundamentales, permite la afirmación y tutela de la propia identidad en virtud del reconocimiento del igual valor de todas las diferencias. Los derechos fundamentales -los de libertad, pero también los sociales- deberían permitir a cada persona y a cada grupo mantener y desarrollar su propia identidad, ya sea en forma individual o colectiva. Obviamente, Ferrajoli asocia el éxito de este modelo a la posibilidad de que existan garantías efectivas para hacer realidad los derechos.

Quizá haría falta agregar un quinto modelo, que permitiera dar cuenta del caso de aquellos ordenamientos que reconocen a la vez el principio general de igualdad y asignan derechos específicos a determinadas minorías; es decir, se trataría de los casos en que las constituciones reconocen a todos por igual 
un cierto número de derechos (lo que podríamos calificar como un "piso mínimo" de derechos), pero a determinados sujetos, por razones de su vulnerabilidad histórica o presente o por alguna de las razones que se explican más adelante se les reconoce unos derechos añadidos (digamos, una cuota "extra" de derechos). Es el caso, según entiendo, de varios ordenamientos modernos, incluido desde luego el mexicano.

\section{LOS ARGUMENTOS SOBRE LOS DERECHOS CULTURALMENTE DIFERENCIADOS}

Luego de ver las posibilidades a través de las cuales el ordenamiento jurídico puede responder a la existencia de diferencias dentro de una determinada comunidad, y aceptando preliminarmente que esas diferencias en efecto deben ser reconocidas a través de la aceptación de que, bajo ciertas circunstancias puede ser adecuado proteger de forma reforzada a un cierto número de sujetos o de grupos, hay que detenerse en los argumentos que puedan sostener la legitimidad de esa opción; se trata, pues, de justificar porqué a ciertos grupos o ciertos individuos que pertenecen a esos grupos se les reconoce un estatuto constitucional distinto (normalmente más protector) que al resto de los habitantes de una comunidad. Pero vamos por partes.

Para el debate multiculturalista la cuestión principal es si para garantizar las diferencias y las identidades étnicas y culturales es necesario crear esferas jurídicas particulares, distintas de aquellas que rigen para la generalidad de los habitantes de un Estado o si, por el contrario, lo que hay que hacer es volver efectivos los derechos fundamentales de forma que se eliminen en la medida de lo posible las desigualdades tan importantes que han sufrido tradicionalmente las minorías. En particular, se trataría de saber si una pertenencia cultural o étnica determinada daría lugar al establecimiento de un status diferenciado -incluso de rango constitucional- para hacer real y efectiva dicha pertenencia.

De acuerdo con las terminología recién expuesta de Ferrajoli, habría que discernir si el Estado constitucional se encuentra en mejores condiciones de realización de la justicia social -sobre todo en lo concerniente a las minorías-, llevando a cabo una "diferenciación jurídica de las diferencias" -aunque optando por realizarla a partir de ciertas características no consideradas violatorias del principio de igualdad tanto formal como sustancial ${ }^{19}{ }_{-}$, manteniendo una "homologación jurídica de las diferencias" o, finalmente, llevando a cabo una "igual valoración jurídica de las diferencias".

Obviamente, el debate no se limita a la discusión sobre el establecimiento o no de derechos culturalmente determinados, sino que se centra también en la supremacía que deberían tener los derechos comunitarios o colectivos sobre

\footnotetext{
19 Se puede decir que, con las variantes que cada ordenamiento constitucional prevea, son violatorias prima facie del principio de igualdad las distinciones basadas sobre la raza, el sexo, la clase social, la religión y la preferencia sexual, entre otras.
} 
los individuales y viceversa. Las posiciones en este punto son muy diversas, pero reflejan fielmente el debate de fondo entre liberales y comunitaristas.

La postura a favor de incluir y garantizar derechos diferenciados en razón de grupos se puede sintetizar, como lo hace Kymlicka ${ }^{20}$, en los siguientes tres puntos:

A) El argumento de la igualdad.- se sostiene que algunos derechos culturalmente diferenciados no necesariamente crean desigualdades, sino que a veces las eliminan. Pudiera ser que la pertenencia a alguna cultura determinada conllevara algún tipo de desigualdad, de forma que los derechos diferenciados vendrían a corregir esa desventaja.

Este argumento mantiene que la estructura estatal no es ni puede ser culturalmente neutral en su actuación, de forma que se producen probables discriminaciones (y potenciales situaciones de desigualdad) siempre que el Estado fija la lengua oficial, los planes educativos que se siguen en las escuelas o las divisiones territoriales y administrativas hacia el interior de su territorio; estas medidas, en palabras de Habermas, afectan a "la autocomprensión ética de una nación"21.

Para compensar lo anterior, se afirma, se deben asegurar a las minorías ciertos derechos que les aseguren un mínimo de condiciones de igualdad con respecto a las ventajas que tendrían otros grupos. Por ejemplo, se pide que si la lengua oficial de un Estado es distinta de la que utiliza una minoría étnica, ésta última pueda tener acceso a traductores en los procesos judiciales en los que se vean involucrados sus miembros o que existan subvenciones estatales para mantener escuelas en las que se enseñe también la lengua de la minoría.

Esta perspectiva, evidentemente, parte del entendimiento de la igualdad en sentido "sustancial", es decir, como realización fáctica de una cierta igualación social, diversa de la igualdad "formal" que se asegura, por ejemplo, a través de la prohibición de leyes individuales.

B) El argumento de los pactos o acuerdos históricos.- un segundo argumento mantiene que, en virtud de la incorporación de ciertos grupos dentro de unidades estatales más amplias, pueden haberse suscrito pactos o acuerdos históricos que preserven ciertos derechos para esos grupos y que habría que respetar y garantizar. Este punto de vista encuentra su apoyo en importantes pactos internacionales que reconocen el derecho a la autodeterminación de los pueblos ${ }^{22}$; dicha autodeterminación comprende no

\footnotetext{
${ }^{20}$ Ciudadanía Multicultural, cit., capítulo VI.

21 "La lucha por el reconocimiento en el Estado democrático de derecho", cit., p. 206. Sobre el principio de neutralidad del Estado, Da Silveira, Pablo, "Neutralidad del Estado y Respeto del Pluralismo. Una defensa del perfeccionismo modesto", La Política. Revista de Estudios sobre el Estado y la Sociedad, número 4, Barcelona, Paidós, octubre de 1998, p. 117 y ss., así como Torbisco, Minorías Culturales y Derechos Colectivos, cit., capítulos VI y VII.

${ }^{22}$ Ver Lucas, Javier de, "Las Minorías: de los derechos individuales al estatuto jurídico", Isonomía, número 3, México, octubre de 1995, p. 71 y ss., así como el artículo 27 del Pacto Internacional de
} 
solamente la posibilidad de constituir un Estado independiente, sino también la de fijar los términos en que se puede producir una unión de pueblos a través, por ejemplo, de una federación.

C) El argumento sobre el valor de la diversidad cultural.- Un tercer argumento a favor de los derechos diferenciados se fundamenta en el juicio de que es valiosa la existencia de culturas diversas, ya que dicha diversidad contribuye a enriquecer la vida de las personas. Además, la existencia de otras culturas permite observar modelos alternativos de organización de los cuales pueden tomarse elementos útiles para la reforma y mejoramiento de las organizaciones sociales ${ }^{23}$. Por otro lado, la existencia de paisajes culturales distintos, desde un punto de vista puramente estético, crea un mundo más interesante. Para Kymlicka este argumento no sirve para justificar por sí solo derechos de las minorías ${ }^{24}$.

Cabe apuntar que a veces el argumento del valor de la diversidad cultural se usa de modo incorrecto para derivar de la simple existencia benéfica del pluralismo cultural, la necesidad de reconocer como valiosas todas las prácticas culturales, asumiendo un relativismo ético inaceptable y que en algunas ocasiones choca con el más elemental sentido de la democracia o, en situaciones extremas, con el todavía más básico concepto de la dignidad humana.

Como dice Rodolfo Vázquez, poco se avanza en el debate multiculturalista si, "sobre la base de un pluralismo mal entendido, se piensa que todas las culturas tienen igual valor y todas merecen igual respeto. Esta premisa es falsa",25.

En efecto, del hecho de que se reconozcan los beneficios de la existencia de un conjunto de culturas distintas, no se puede derivar que todas esas culturas merezcan el mismo respeto ${ }^{26} \mathrm{y}$, por tanto, no se les deben reconocer a todas derechos diferenciados solamente por ser distintas de las culturas mayoritarias, sin tomar en cuenta la compatibilidad de sus prácticas y

Derechos Civiles y Políticos, la Declaración de la O.N.U. sobre los derechos de las personas pertenecientes a minorías nacionales o étnicas, religiosas y lingüísticas (del 18 de diciembre de 1990) y el Convenio 169 de la O.I.T. sobre pueblos indígenas y tribales en Estados independientes (en vigor a partir del 5 de septiembre de 1991).

${ }^{23}$ Como escribe Torbisco, "En la medida en que una sociedad multicultural incrementa las oportunidades de realizar opciones culturales más allá de las estrechas fronteras del grupo al que pertenecemos, el multiculturalismo es capaz de transformar, eventualmente enriqueciendo, el horizonte de significados disponible para quienes no son miembros de una cultura", Minorías Culturales y Derechos Colectivos, cit., p. 523.

${ }^{24}$ Ciudadanía Multicultural, cit., p. 171.

25 "Derechos de las Minorías y Tolerancia", Diánoia. Anuario de Filosofía, número 43, México, 1997, p. 159.

${ }^{26}$ Garzón Valdés señala que "La verificación de diferentes costumbres -conjuntamente con sus implicaciones normativas- no permite inferir sin más el respeto incondicionado de esas mismas costumbres", "El problema ético de las minorías étnicas", cit., p. 526. Ver también, en sentido parecido, las consideraciones de Luigi Ferrajoli, "Los fundamentos de los derechos fundamentales", cit., p. 364-365. 
costumbres con -por lo menos- los postulados básicos de la democracia y la dignidad de todas las personas.

Esta es una de las deficiencias del debate multiculturalista, el cual normalmente se realiza en términos abstractos cuando lo necesario es llevarlo a cabo a la vista de grupos y comunidades concretos, los cuales -en virtud, precisamente, del pluralismo existente- no pueden ser todos puestos en el mismo saco.

En contra de los derechos culturalmente diferenciados y de su prevalencia sobre los derechos individuales se esgrimen los siguientes argumentos ${ }^{27}$ :

A) El argumento del individualismo ético.- este argumento sostiene que los individuos valen más que los grupos a los que pertenecen y las culturas valen en cuanto tienen valor los individuos que las comparten. Por ello, los derechos comunitarios deben ceder si entran en conflicto con los derechos liberales, entendidos como valores que hay que atribuir a cada individuo en cuanto ser único e irrepetible.

B) El argumento de la imparcialidad.- este argumento coincide con el punto de vista expresado párrafos arriba en el sentido de que no todas las culturas deben ser toleradas o respetadas por igual. Añade que para resolver los conflictos interculturales se precisa de un metacriterio que puede ser la perspectiva kantiana del liberalismo. De acuerdo con este argumento se acepta un multiculturalismo "débil" que circunscribe las peculiaridades éticamente respetables o tolerables a tres ámbitos fundamentales: la lengua, el arte y las necesidades o deseos secundarios de las personas ${ }^{28}$.

\section{5. ¿QUÉ DERECHOS PARA LAS SOCIEDADES MULTICULTURALES?}

Tomando como base los anteriores argumentos toca ahora exponer de qué derechos en concreto se estaría hablando cuando se hace referencia a derechos culturalmente diferenciados. A la existencia, reconocimiento y garantía de los derechos que se mencionan a continuación deben aplicarse, según sea el caso, los argumentos que se acaban de mencionar en el apartado anterior.

Según Kymlicka, que utiliza una perspectiva liberal o liberal moderada, hay tres tipos de derechos diferenciados en función del grupo ${ }^{29}$ :

A) Los derechos de autogobierno.- por este tipo de derechos podemos entender los que son reconocidos a uno o más grupos minoritarios dentro de un Estado, de acuerdo con los cuales pueden diseñar y ejercer de forma autónoma atribuciones de carácter político y/o jurisdiccional. Una forma concreta que

\footnotetext{
${ }^{27}$ Vázquez, Rodolfo, "Derechos de las Minorías y Tolerancia”, cit., p. 156 y ss. Una crítica general a los postulados multiculturalistas se puede ver en Vitale, Ermanno, Liberalismo e Multiculturalismo. Una Sfida per el Pensiero Democratico, Roma-Bari, Laterza, 2000.

${ }^{28}$ Vázquez, Rodolfo, "Derechos de las Minorías y Tolerancia”, cit., p. 161.

${ }^{29}$ Ciudadanía Multicultural, cit., p. 46 y ss. Un análisis complementario puede verse en Levy, Jacob T., El Multiculturalismo del Miedo, Madrid, Tecnos, 2003, p. 167 y ss.
} 
pueden tomar estos derechos es el federalismo; en un Estado federal las competencias gubernativas se encuentran divididas entre los diferentes niveles de gobierno, de forma tal que las subunidades regionales cuentan con márgenes más o menos amplios para determinar sus estructuras y formas de organización política (siempre dentro del marco que establece la Constitución federal, por supuesto) ${ }^{30}$.

Kymlicka señala que, en principio, no hay una conexión necesaria entre el federalismo y la diversidad cultural, aunque reconoce también que esta forma de distribución del poder estatal constituye una estrategia común para acomodar a las minorías nacionales ${ }^{31}$. Otros autores destacan que la organización federal dentro de los Estados democráticos juega un papel muy importante para controlar a las mayorías y, en consecuencia, para proteger a las minorías ${ }^{32}$.

Obviamente, el federalismo servirá para dar cabida a la diversidad cultural en la medida en que la o las minorías nacionales sean mayoritarias dentro de las unidades regionales o esas mismas minorías puedan estar en condiciones de tener una representación política propia del territorio subnacional; de lo contrario, la división territorial del Estado solamente servirá para reproducir el dominio mayoritario que existe a nivel nacional ${ }^{33}$.

B) Derechos poliétnicos.- estos derechos tienen por objetivo erradicar las discriminaciones y los prejuicios existentes contra las minorías culturales. Se concretan en la exigencia de subvención pública para las prácticas culturales de las comunidades o para tener acceso en condiciones de cierta igualdad a los mercados de intercambio de bienes y servicios. Bajo ciertas modalidades, algunos grupos en los que no existen diferencias entre la moral pública y la moral privada (y en los que, por tanto, la religión es una forma de poder sobre la comunidad) reivindican la exención de leyes y disposiciones que perjudiquen sus prácticas religiosas. Tal es el caso, recordado por Kymlicka, de la negativa a usar casco de seguridad para motocicletas de los varones sijs en Canadá, de forma que puedan seguir utilizando sus turbantes. En Inglaterra los judíos y musulmanes han solicitado que se les exima del cierre dominical de los negocios o de las normas relativas al sacrificio de los animales. En México los niños que profesan algunas religiones se niegan a rendir culto

\footnotetext{
${ }^{30}$ Una descripción de la forma en que se encuentran distribuidos los ámbitos competenciales entre la Federación y las entidades federativas en México puede verse en Carbonell, Miguel, Constitución, Reforma Constitucional y Fuentes del Derecho en México, $6^{a}$ edic., México, IIJ-UNAM, Porrúa, 2008.

${ }^{31}$ Ciudadanía Multicultural, cit., p. 49.

${ }^{32}$ En este sentido, Alfred Stepan, "Democrazia y Federalismo. Un'analisi Comparata", Rivista Italiana di Scienza Politica, año XXVIII, abril de 1998, p. 5-53. Sobre el mismo punto, Linz, Juan J., "Democracia, Multinacionalismo y Federalismo", Revista Española de Ciencia Política, volumen 1, número 1, Madrid, 1999, p. 7-40.

${ }^{33}$ Kymlicka, Ciudadanía Multicultural, cit., p. 50; ver también las observaciones de Habermas, "La lucha por el reconocimiento en el Estado democrático de derecho", cit., p. 208-209.
} 
en las escuelas públicas a los símbolos patrios como la bandera o el himno nacionales ${ }^{34}$.

Una característica de este tipo de derechos es que, en principio, no obstaculizan el éxito y la viabilidad de las instituciones políticas y económicas de las sociedades dominantes, con lo cual no plantean prima facie un conflicto con algún otro tipo de derecho.

C) Derechos especiales de representación.- estos derechos tienen por objetivo compensar algunas desviaciones o insuficiencias de los procesos de representación política de los Estados democráticos contemporáneos. En este sentido, algunos grupos han pugnado por establecer algo así como una "acción de clase política", que compense de forma temporal algunas desventajas o barreras sistémicas que les impiden contar con una efectiva representación política ${ }^{35}$. Entre estas desventajas se menciona, por ejemplo, la imposibilidad que tienen algunas minorías de establecer alianzas con otros grupos sociales, lo cual las coloca en una situación de inferioridad real respecto de los demás grupos ${ }^{36}$.

Las críticas hacia este tipo de derechos se estructuran, por lo menos, a partir de una doble vertiente. En primer lugar, sostienen que los problemas de la representación política no son exclusivos de los grupos culturalmente diferenciados, sino de toda la sociedad. No hay prácticamente ningún Estado democrático que haya podido solucionar de modo eficaz el tema de la representación política ${ }^{37}$. El predominio de las burocracias partidistas, los efectos nocivos del corporativismo, la influencia de los grupos de presión, entre otros, son fenómenos que alteran el concepto y funcionamiento de la representación política y que explican en alguna medida el descontento popular respecto del desempeño de los órganos representativos.

En segundo lugar, se dice que los mismos derechos especiales de representación deberían asignarse -si se acepta la postura de quienes defienden estos derechos- a otros grupos, no necesariamente minoritarios, pero que también tienen problemas para ser efectivamente representados. El caso paradigmático al respecto es el de las mujeres, las cuales en casi todos los países tienen un notable índice de subrrepresentación respecto de los hombres si se toma en cuenta el porcentaje del total de la población que son. Argumentos parecidos se podrían sostener para el caso de los discapacitados,

\footnotetext{
${ }^{34}$ Sobre este último punto, Cázares, Carlos y Peña de Hoyos, José Luis, "Los Testigos de Jehová y la Objeción de Conciencia" en VV.AA., La Objeción de Conciencia, México, IIJ-UNAM, 1998, p. 255-268.

${ }^{35}$ Kymlicka, Ciudadanía Multicultural, cit., p. 54.

${ }^{36}$ Sullivan, Kathleen M., "Representation of Racial Minorities" en Brinkley, Alan, Polsby, Nelson W. y Sullivan, Kathleen M., The New Federalist Papers. Essays in Defense of the Constitution, W.W. Norton and Company, New York-Londres, 1997, p. 104. Ver también González Galván, "Los Paradigmas Constitucionales y los Derechos Indígenas", cit., p. 100.

${ }^{37}$ Sartori, Giovanni, "En Defensa de la Representación Política", Claves de Razón Práctica, número 91, Madrid, abril de 1999, p. 2 y ss.
} 
de los pobres, etcétera. Se trata del conocido argumento de "la pendiente resbaladiza": si comenzamos reconociendo una representación especial para las minorías étnicas terminaremos haciendo lo mismo con otros grupos discriminados.

Desde mi punto de vista, lo que cabría hacer en este campo son al menos dos cosas, una de alcance particular y otra de tipo más general: a) por un lado intentar construir una "representación de grupo", quizá mediante el establecimiento de uno o varios distritos electorales indígenas, que pudieran escoger representantes ante las cámaras legislativas federales y locales exclusivamente entre sus miembros; y b) por otro lado, habría que mejorar, en general, los mecanismos representativos del Estado; esto se puede lograr si se democratizan internamente los partidos políticos, si se establecen mecanismos de accountability para los representantes populares, si se crean sistemas de fiscalización de ingresos y gastos para las campañas políticas, etcétera.

Tales medidas traerían beneficios no solamente para los grupos culturalmente diversos, sino para toda la sociedad, con lo cual se verían satisfechas las reivindicaciones de esos grupos. La idea de transitar hacia una democracia "postrepresentativa" no parece ni posible ni deseable de momento ${ }^{38}$, lo cual, sin embargo, no quiere decir que no se puedan intentar innovaciones a los sistemas representativos que se utilizan en el presente.

Una forma parcialmente distinta de las señaladas para avanzar hacia una mejor protección de las minorías, sin producir alteraciones graves en el sistema de representación política que han consagrado la mayoría de Estados democráticos, quizá pudiera darse al momento de definir la conformación de los distritos electorales. Al establecer las "demarcaciones del voto" se pueden tomar en cuenta la relación mayoría-minorías, de tal forma que las segundas puedan contar con una gama de opciones que les permita tener posibilidades de elegir a sus propios representantes.

En Estados Unidos la integración de los Ilamados "majority-minority congressional districts" ha producido que para las elecciones de 1994 el número de miembros afroamericanos de la Cámara de Representantes pasara de 17 a 39. De esos 39, solamente tres representantes no fueron elegidos en distritos conformados bajo el criterio de "majority-minority" luego la Corte Suprema de los Estados Unidos ha limitado esa práctica por considerarla no apegada a la Constitución ${ }^{40}$, tal vez los mismos parámetros se puedan tomar en cuenta en aquellos Estados en los que la base de definición de los distritos no tenga que ser racial, pero pueda ser cultural o étnica.

Un teórico muy relevante, Jacob T. Levy, ha elaborado una síntesis de los tipos de derechos culturales o colectivos que suelen estar presentes tanto

\footnotetext{
${ }^{38}$ Sartori, "En Defensa de la Representación Política", cit., p. 6.

${ }^{39}$ Sullivan, Kathleen M., "Representation of Racial Minorities", cit., p. 106.

${ }^{40}$ Ver Ceccherini, Eleonora, "Eguaglianza del Voto e Rappresentativitá delle Minoranze: recenti orientamenti giurisprudenziali negli Stati Uniti", Quaderni Costituzionali, número 2 de 1997, p. 311 y ss.
} 
en los discursos teóricos como en las políticas públicas de los Estados multiculturales $^{41}$. Se trata de una lista que comprende tanto aquellas reivindicaciones que pueden parecer legítimas desde una óptica liberal, como otras que quizá no lo sean tanto. Pero la discusión sobre la legitimidad de cada una de las especies que a continuación se exponen es algo que puede hacerse solamente a partir de su conocimiento y análisis, y no de forma previa.

Los principales derechos culturales o colectivos son, de acuerdo con Levy, los siguientes:

A) Exenciones a leyes que penalizan o dificultan prácticas culturales; en este rubro se incluirían las exenciones de la prohibición de usar el peyote para ciertas tribus indígenas o de la obligación para los miembros de la tribu Sikh de quitarse el turbante para poder ponerse el casco al viajar en motocicleta. También sería el caso de quienes, profesando la religión judía, piden que se les exente del cierre dominical obligatorio de los comercios, en aquellos países donde tal medida existe.

B) Asistencia para llevar a cabo una serie de acciones que la mayoría puede realizar sin ayuda. Se trata, sobre todo, de pedir subvenciones públicas para llevar a cabo festivales tradicionales, para impulsar la difusión de su propia lengua o para fundar asociaciones étnicas.

C) Autogobierno para las minorías étnicas, culturales o nacionales. Dentro de esta categoría se incluyen las demandas de secesión, de autonomía gubernativa -por ejemplo a través del federalismo- o jurisdiccional -jurisdicciones indígenas, penas diferenciadas en razón de la pertenencia étnicas, etcétera-.

D) Reglas externas consistentes en la restricción de ciertas libertades para los no-miembros de la comunidad, establecida para la protección de la cultura de la comunidad. Como ejemplos Levy menciona las restricciones al inglés en Quebéc o al ejercicio del voto dentro de ciertas comunidades indígenas para los que no pertenecen a su grupo étnico. Otro ejemplo sería la prohibición de adquirir tierras o propiedades de los miembros de la minoría.

E) Reglas internas que buscan normar hacia dentro del grupo la conducta de sus miembros; ejemplos de las reglas internas lo son las prohibiciones para casarse con una persona que no pertenezca al grupo o la obligación de vestirse de cierta forma (como en el caso de los talibanes en Afganistán). Sobre estas reglas, Torbisco apunta que "desde una óptica liberal, parece claro que el Estado no puede legítimamente imponer tales reglas, pero ¿qué ocurre si las impone un grupo a sus miembros?"42. El reconocimiento de este tipo de reglas implica la reproducción al interior de las minorías de lo que se quiere evitar en la relación minoría-mayoría. Además, bajo determinados contextos culturales, puede suponer la preservación jurídica de una serie de prácticas que serían reprobables desde el punto de vista moral; como afirma Garzón Valdés,

\footnotetext{
${ }^{41}$ Levy, Jacob T., El Multiculturalismo del Miedo, cit., p. 167 y ss.

42 Torbisco, Neus, Minorías Culturales y Derechos Colectivos: un enfoque liberal, cit., p. 163.
} 
"si la conservación de la identidad o de la unidad familiar dependen de prácticas crueles y denigrantes como la circuncisión femenina, esa identidad o esa unidad carecen de toda justificación desde el punto de vista moral... no entiendo por qué... el Estado deba fomentar la existencia de concepciones culturales que no benefician a quienes las practican"43.

F) Reconocimiento/obligatoriedad de sus prácticas jurídicas por el sistema jurídico de la mayoría. Se trataría de la exigencia de reconocimiento a las prácticas jurídicas de los grupos étnicos y culturales; en parte, esta reivindicación está unida a la de autogobierno. En México el artículo $2^{\circ}$ ofrece ya una base constitucional bastante detallada para llevar a cabo el reconocimiento de las prácticas jurídicas indígenas. Conviene decir, de nuevo, que el reconocimiento de las prácticas jurídicas de los grupos étnicos o culturales no puede darse en el vacío, sin tomar en cuenta las peculiaridades de cada grupo concreto y su mayor o menor compatibilidad con, al menos, una serie mínima de derechos fundamentales que deben ser aceptados por todos $^{44}$.

G) Representación adecuada de las minorías en los cuerpos legislativos de las mayorías; dicha representación tendría que estar de algún modo garantizada o facilitada por el propio sistema jurídico. Se trataría de una representación de grupo, que por ejemplo reservara un determinado porcentaje de los puestos electivos a los miembros de una minoría ${ }^{45}$. Otra posibilidad consistiría en delimitar los distritos electorales de tal forma que las minorías fueran mayoría dentro de un determinado distrito, con lo cual se les podría dar la oportunidad de elegir a un representante afín a sus preocupaciones, pero sin limitarlas a la elección de los miembros del grupo.

H) Demandas simbólicas, que comprenden cuestiones que tienen que ver con los elementos simbólicos que identifican a una determinada comunidad; tal es el caso de las festividades y los himnos nacionales o de los contenidos de la historia oficial.

Del elenco recién trascrito se puede observar que los derechos colectivos, en principio, son tanto derechos que tienen los individuos que pertenecen a una cierta comunidad, en razón justamente de esa pertenencia; como los derechos que tiene un grupo minoritario en relación con (o frente a) la mayoría.

\footnotetext{
${ }^{43}$ Garzón Valdés, Ernesto, "Cinco Confusiones acerca de la Relevancia Moral de la Diversidad Cultural", Claves de Razón Práctica, número 74, Madrid, julio-agosto de 1997, p. 20.

${ }^{44}$ No deja por ello de ser sorprendente el contenido de la fracción I del apartado A del artículo $2^{\circ}$, que establece: "Esta Constitución reconoce y garantiza el derecho de los pueblos y las comunidades indígenas a la libre determinación y, en consecuencia, a la autonomía para: I. Decidir sus formas internas de convivencia y organización social, económica, política o cultural". Por fortuna, esta manifestación de relativismo cultural se encuentra matizada en la fracción II del mismo apartado, que impone el respeto a las "garantías individuales" y los "derechos humanos" por parte de los integrantes de las comunidades indígenas.

${ }^{45}$ Young, Iris Marion, La Justicia y la Política de la Diferencia, trad. de Silvina Alvarez, Madrid, Ediciones Cátedra, 2000.
} 
Por ejemplo, las exenciones a algunas de las leyes de la mayoría son sin duda de tipo individual, pero reconocidas por razón de una pertenencia étnica o cultural; por otro lado, el derecho a la autodeterminación, al autogobierno o a las demandas simbólicas sólo tiene sentido si se otorga al grupo entendido complexivamente y no a cada uno de sus individuos.

El reconocimiento de algunos de estos tipos de derechos (pre)supone, entre otras cuestiones, considerar que nuestros ordenamientos jurídicos -incluyendo los ordenamientos de los países democráticos- asumen un determinado punto de vista cultural, religioso, sexual, político, etcétera; esto significa que ni el ordenamiento jurídico ni las instituciones públicas que actúan bajo su amparo son neutrales frente a las diversas opciones culturales, religiosas, sexuales, políticas, etcétera. Por ejemplo, ¿cómo se puede dudar de que el cierre o descanso dominical de los establecimientos mercantiles es una norma tomada de la religión católica?, como lo es también el matrimonio heterosexual, la previsión como delito del adulterio (o incluso, en el pasado, de la sodomía), y así por el estilo.

Por otro lado, el reconocimiento de derechos colectivos también se da con base en la (pre)suposición de que, en los Estados multiculturales, el ordenamiento jurídico y las instituciones públicas no pertenecen solamente a la mayoría, ni deben servir para privar a las minorías de sus propias prácticas culturales (siempre que las minorías, desde luego, estén dispuestas a respetar un mínimo ético de reglas de convivencia $)^{46}$.

Una cosa es que el Estado, sus reglas y sus instituciones no sean neutrales y otra muy distinta es que el propio Estado sea administrado como si perteneciera a uno sólo de los grupos que conforman una sociedad. Entre una cosa y otra hay, evidentemente, una buena distancia, que viene a ser la misma que existe entre un Estado democrático y un Estado totalitario.

En alternativa a lo anterior, algunos autores como Juan Antonio Cruz Parcero o Neus Torbisco han intentado una ruta alternativa para identificar a los derechos colectivos; para ellos, tales derechos serían distintos a los tradicionales derechos individuales en la medida en que tienen por objeto bienes que no son individualizables ${ }^{47}$, es decir, bienes que les son útiles a los

\footnotetext{
${ }^{46}$ La idea de que las instituciones estatales no deben pertenecer a ninguno de los grupos que conviven dentro de un Estado multicultural se toma de Raz, Joseph, "Multiculturalism: a liberal view" en Raz, J., Ethics in the Public Domain. Essays in the Morality of Law and Politics, Oxford, Clarendon Press, 1994, p. 159.

${ }^{47}$ Torbisco, Neus, "El Debate sobre los Derechos Colectivos de las Minorías Culturales. Una Reflexión sobre la Adecuación de las Premisas Teóricas" en Carbonell, Miguel, Cruz Parcero, Juan Antonio y Vázquez, Rodolfo (compiladores), Derechos Sociales y Derechos de las Minorías, cit.; Cruz Parcero, Juan Antonio, "Sobre el Concepto de Derechos Colectivos", Revista Internacional de Filosofía Política, número 12, Madrid, 1998; una posición relativamente escéptica sobre los derechos colectivos puede verse en López Calera, Nicolás, ¿Hay Derechos Colectivos? Individualidad y Socialidad en la Teoría de los Derechos, Barcelona, Ariel, 2000.
} 
individuos en la medida en que pertenecen a un grupo ${ }^{48}$. Es otra forma, igualmente útil e interesante, de acercarse al tema y que pone también de manifiesto las limitaciones que tienen las teorías tradicionales en materia de derechos fundamentales.

\section{A MODO DE CONCLUSIÓN: LOS DILEMAS DE LOS DERECHOS DE GRUPO}

La aceptación de los tipos de derechos que se acaban de mencionar, con las modalidades que se quieran, supone dar un paso adelante con respecto a los argumentos que limitan los derechos en razón de grupo a la lengua, el arte o las necesidades secundarias de los individuos, pero también implica una limitación importante para quienes consideran que los grupos pueden tener derechos por su simple existencia y que, además, tales derechos colectivos deben prevalecer aún en el caso de que entren en conflicto con los derechos individuales. La cuestión parece ser un poco más compleja de lo que podrían suponer quienes se ubican en ambos extremos del debate.

Como sostiene Ferrajoli, un cuadro de derechos fundamentales bien diseñado, con un sistema de garantías apropiado, es suficiente para asegurar una igualdad que permita a cada individuo proteger y hacer uso de su propia identidad. Contando con ese marco general, las posibilidades de acción de la legislación secundaria son muchas; a través de un ejercicio legislativo responsable se puede perfectamente dar cabida a las necesidades y deseos de las personas que integran los grupos culturalmente diversos. Esto no excluye que un estatus jurídico diferenciado para las minorías étnicas no se pueda integrar directamente en el texto constitucional.

Quizá la misión principal que tienen frente a sí las sociedades democráticas en las que conviven diversas naciones y nacionalidades sigue siendo la muy básica de lograr una cierta homogeneidad social, entendiendo por ella no la posibilidad de arrasar con todas las diferencias, sino el establecimiento de un orden social que permita a todos los miembros de la comunidad el goce de los derechos vinculados con la satisfacción de sus bienes básicos, para utilizar las palabras de Ernesto Garzón Valdés. De acuerdo con este mismo autor, los bienes básicos son aquellos que son condición necesaria para la realización de cualquier plan de vida, es decir, para la actuación del individuo como agente moral ${ }^{49}$. A partir del aseguramiento de esos bienes básicos se pueden explorar algunas modalidades de los derechos culturalmente diferenciados como las que ya se han mencionado más arriba.

Lo anterior no obsta para reconocer que los derechos colectivos pueden tener dificultades de encaje dentro de una teoría liberal de la sociedad. Obviamente, la forma de hacer convivir a los derechos de grupo o colectivos en sociedades que propugnan como valores básicos la libertad y la igualdad

\footnotetext{
48 Sobre el concepto de "bien colectivo" como objeto de los derechos fundamentales, Alexy, Robert, El Concepto y la Validez del Derecho, Barcelona, Gedisa, 1994, p. 179 y ss.

49 "El problema ético de las minorías étnicas", cit., p. 531.
} 
de los ciudadanos no es una tarea fácil ni que pueda resolverse de un solo plumazo.

Una manera de hacer que los derechos colectivos no choquen con el pensamiento liberal que concibe al individuo como el único agente moral válido dentro de la sociedad, consiste en distinguir entre las reivindicaciones que podrían hacer los grupos étnicos o culturales hacia dentro de sus comunidades (y que, por tanto, podrían aplicar sobre sus miembros) y aquellas otras que se proyectarían hacia fuera de las mismas (en su relación con otros grupos). A las primeras Kymlicka las llama "restricciones internas" y tienen por objeto proteger al grupo del impacto que podría tener el disenso interno ${ }^{50}$. A las segundas el mismo autor las denomina "protecciones externas", cuya misión sería proteger al grupo de las decisiones políticas y económicas de la mayoría.

En general, para un punto de vista liberal resultan inaceptables las restricciones internas. Habermas en este punto niega la posibilidad de que el multiculturalismo se deba mantener artificialmente, con un sentido de protección administrativa de las especies. Por el contrario, sostiene este autor, las posibilidades de sobrevivencia de una cultura se mantienen mientras esa cultura siga convenciendo a sus miembros, motivando una apropiación productiva y una prosecución de la misma. Por tanto, una garantía jurídicamente asegurada de la supervivencia de una cultura le robaría a sus miembros la opción de decidir continuar perteneciendo a la misma o de determinar si ha llegado el momento de abandonarla. La posibilidad de toda persona de confrontar a su propia cultura siempre debe quedar abierta ${ }^{51}$.

Como señala Fernando Salmerón, "es verdad que los compromisos y lealtades que dan sentido a las vidas individuales encarnan siempre en las prácticas sociales de una cultura, pero lo hacen por decisión libre de una persona, y con una adhesión que no pierde nunca la capacidad crítica, ni la capacidad de abandonar en bloque la cultura de origen"52.

El hecho de negar a los grupos étnicos o culturales la posibilidad de imponer sobre sus propios miembros (incluso en contra de su voluntad) algunos derechos de tipo colectivo no implica, sin embargo, tratar de diluir o erosionar su sentido de pertenencia. Por el contrario, es justamente en un contexto democrático, basado en la libertad del sujeto y en un mínimo de

\footnotetext{
${ }^{50}$ El tema de las "restricciones internas" es de una importancia capital para el correcto entendimiento de la protección de las minorías, ya que tiene que ver con las llamadas "minorías dentro de las minorías", es decir, con los grupos minoritarios que conviven dentro de otro grupo que a su vez es minoría con respecto a un grupo distinto. Sobre el punto, Green, Leslie, "Internal Minorities and their Rights" en Kymlicka, Will (editor), The Rights of Minority Cultures, Oxford, Oxford University Press, 1995, p. 256 y ss.

${ }^{51}$ Las ideas anteriores se encuentran en Habermas, "La Lucha por el Reconocimiento en el Estado Democrático de Derecho", cit., p. 210-211; en el mismo sentido, Kymlicka, Ciudadanía Multicultural, cit., p. 59.

${ }^{52}$ Diversidad Cultural y Democracia, cit., p. 32.
} 
igualdad formal y sustancial, en donde más se pueden potenciar los sentidos naturales de pertenencia de los ciudadanos ${ }^{53}$.

Esa misma pertenencia, a su vez, juega en favor de la democracia al potenciar la responsabilidad, el interés y la participación ciudadana en los asuntos públicos. En este sentido, Alain Touraine señala que "No hay democracia sin conciencia de pertenencia a una colectividad política, una nación en la mayoría de los casos, pero también una comuna, una región y hasta un conjunto federal..."

La eliminación de las restricciones internas también se ubica en la línea de asegurar a los individuos su calidad de agentes morales; en ese sentido, por ejemplo, "los representantes de las comunidades indígenas deben estar dispuestos a abandonar reglas o principios de comportamiento si, dadas las circunstancias actuales, ellos contribuyen a aumentar su vulnerabilidad" ${ }^{\prime 5}$.

Por lo que hace a las "protecciones externas", me parece que la tradición liberal no tendría tanto problema en aceptarlas con base en la idea de la equidad que debe privar entre grupos y en el principio de igualdad de los derechos de los sistemas de vidas culturales ${ }^{56}$, aunque habría que ver las formas concretas que toman dichas protecciones. Quizá en este punto se deba enfatizar, de nuevo, las enormes posibilidades que ofrece un sistema de derechos fundamentales bien armado y que tenga las garantías necesarias y suficientes para ser efectivo en la realidad.

\section{REFERENCIAS}

ALEXY, Robert. El Concepto y la Validez del Derecho. Barcelona: Gedisa, 1994.

ARAGÓN, Manuel. La Constitución como Paradigm. In Teoría de la Constitución. Ensayos Escogidos. México: IIJ-UNAM, Porrúa, 2000.

BEREZIN, Mabel. Introduction. Democracy and Others in the Global Polity. International Sociology. vol. 14, número 3, Londres, setembro 1999.

CARBONELL, Miguel. Constitución, Reforma Constitucional y Fuentes del Derecho en México. 6a edic., México: IIJ-UNAM, Porrúa, 2008.

. El Canon Neoconstitucional. Madrid: Trotta, 2010.

. VÁZQUEZ, Rodolfo (Orgs.). Estado Constitucional y Globalización. México, IIJ-UNAM: Porrúa, 2001.

CÁZARES, Carlos; PEÑA DE HOYOS, José Luis. Los Testigos de Jehová y la Objeción de Conciencia. in La Objeción de Conciencia. México: IIJ-UNAM, 1998.

CECCHERINI, Eleonora. Eguaglianza del Voto e Rappresentativitá delle Minoranze: recenti orientamenti giurisprudenziali negli Stati Uniti. Quaderni Costituzionali. número 2, 1997.

\footnotetext{
${ }^{53}$ Berezin, Mabel, "Introduction. Democracy and Others in the Global Polity", International Sociology, vol. 14, número 3, Londres, septiembre de 1999, p. 227 y ss.

54 ¿Qué es la Democracia?, México, FCE, 1998, p. 99.

55 Garzón Valdés, “El Problema Ético de las Minorías Étnicas”. cit., p. 534 y 536.

${ }^{56}$ Habermas, "La Lucha por el Reconocimiento en el Estado Democrático de Derecho", cit., p. 191.
} 
CRUZ PARCERO, Juan Antonio. Sobre el Concepto de Derechos Colectivos. Revista Internacional de Filosofía Política. Número 12, Madrid, 1998.

DA SILVEIRA, Pablo. Neutralidad del Estado y Respeto del Pluralismo. Una Defensa del Perfeccionismo Modesto. La Política. Revista de Estudios sobre el Estado y la Sociedad. Número 4, Barcelona: Paidós, outubro 1998.

FERRAJOLI, Luigi. Igualdad y Diferencia. in Derechos y Garantías. La Ley del más Débil. Madrid: Trotta, 1999.

. Los Fundamentos de los Derechos Fundamentals. 3. ed., Madri: Trotta, 2007.

GARZÓN VALDÉS, Ernesto. Cinco Confusiones acerca de la Relevancia Moral de la Diversidad Cultural. Claves de Razón Práctica. Número 74, Madrid, julho-agosto 1997.

. El Problema Ético de las Minorías Étnicas. In OLIVÉ, L. (Org.). Ética y Diversidad Cultural. México: Fondo de Cultura Económica, 1993.

GREEN, Leslie. Internal Minorities and Their Rights. In KYMLICKA, Will (Ed.). The Rights of Minority Cultures. Oxford: Oxford University Press, 1995.

HABERMAS, Jürgen. La Lucha por el Reconocimiento en el Estado Democrático de Derecho. in La Inclusión del Otro. Estudios de Teoría Política. Barcelona: Paidós, 1999.

IANNI, Octavio. La Era de la Globalización. México: Siglo XXI editores, 1999.

KELLAS, James. The Politics of Nationalism and Ethnicity. 2. ed., Nova York: St. Martin's Press, 1998.

KYMLICKA, Will. Ciudadanía Multicultural. Una Teoría Liberal de los Derechos de las Minorías. Barcelona: Paidós, 1996.

Derechos Individuales y Derechos de Grupo en la Democracia Liberal. in DEL AGUILA, Rafael; VALLESPÍN, Fernando et al. La Democracia en sus Textos. Madrid: Alianza Editorial, 1998.

Paidós, 2003.

La Política Vernácula. Nacionalismo, Multiculturalismo y Ciudadanía. Barcelona:

LEVY, Jacob T. El Multiculturalismo del Miedo. Madrid: Tecnos, 2003.

LINZ, Juan J. Democracia, Multinacionalismo y Federalismo. Revista Española de Ciencia Política. Volume 1, número 1, Madrid, 1999.

LÓPEZ CALERA, Nicolás. ¿Hay Derechos Colectivos? Individualidad y Socialidad en la Teoría de los Derechos. Barcelona: Ariel, 2000.

LUCAS, Javier de. Las Minorías: de los derechos individuales al estatuto jurídico. Isonomía. Número 3, México, outubro 1995.

RAZ, Joseph. Multiculturalism: a liberal view. in RAZ, Joseph. Ethics in the Public Domain. Essays in the Morality of Law and Politics. Oxford: Clarendon Press, 1994.

SARTORI, Giovanni. En Defensa de la Representación Política. Claves de Razón Práctica. Número 91, Madrid, abril 1999.

STEPAN, Alfred. Democrazia y Federalismo. Un'analisi Comparata. Rivista Italiana di Scienza Politica. Ano XXVIII, abril 1998.

SULLIVAN, Kathleen M. Representation of Racial Minorities. in BRINKLEY, Alan; POLSBY, Nelson W; SULLIVAN, Kathleen M. The New Federalist Papers. Essays in Defense of the Constitution. New York-Londres: W.W. Norton and Company, 1997. 
TORBISCO, Neus. El Debate sobre los Derechos Colectivos de las Minorías Culturales. Una reflexión sobre la adecuación de las premisas teóricas. in CARBONELL, Miguel; CRUZ PARCERO, Juan Antonio; VÁZQUEZ, Rodolfo (Eds.). Derechos Sociales y Derechos de las Minorías. 2. ed., México: UNAM, Porrúa, 2001.

TOURAINE, Alain. ¿Qué es la Democracia? México: FCE, 1998.

VALLESPÍN, Fernando. El Futuro de la Política. Madrid: Taurus, 2000.

VÁZQUEZ, Rodolfo. Derechos de las Minorías y Tolerancia. Diánoia. Anuario de Filosofía. Número 43. México, 1997.

VITALE, Ermanno. Liberalismo e Multiculturalismo. Una Sfida per el Pensiero Democratico. Roma-Bari: Laterza, 2000.

YOUNG, Iris Marion. La Justicia y la Política de la Diferencia. Madrid: Ediciones Cátedra, 2000. 